\title{
Reverse Logistics Competitiveness Factor And Sustainability In Companies
}

\author{
${ }^{1}$ Adriana de Souza Miranda, ${ }^{2}$ Rosimary Sevalho do Nascimento Santana, ${ }^{3}$ Rosimeire Freires Pereira Oliveira, \\ ${ }^{4}$ Sidney dos Santos Oliveira
}

\author{
${ }^{1}$ Faculdade Estácio Amazonas. Av. Djalma Batista, Chapada-Manaus - Amazonas - Brasil. (cfss.camila@gmail.com) \\ ${ }^{2}$ Faculdade Estácio Amazonas. Av. Djalma Batista, Chapada-Manaus - Amazonas - Brasil. \\ ${ }^{3}$ Faculdade Estácio Amazonas. Av. Djalma Batista, Chapada-Manaus - Amazonas - Brasil. (rosimeirefpol@ yahoo.com.br) \\ ${ }^{4}$ Secretaria de Educação e Desporto-SEDUC-Manaus- Amazonas-Brasil (sidneyoliveira54@ yahoo.com.br)
}

\begin{abstract}
This study aims to conduct a study on reverse logistics that include environmental issues and industrial waste, which currently is a very subject matter, through the concept of sustainable production. The general objective of this research is to evaluate the reverse logistics and its competitive and sustainable potential in organizations. The research is a qualitative approach, used technical procedures will be of the research literature, in order to collect and compile information for analyzing the different positions on the issue of research, will take into account the characteristics that ensure competitiveness and sustainability to companies on track economic, social and environmental through its various business goals. In summary, analyzing the sharp concern for the preservation and survival of the planet in recent decades, reverse logistics has become a strategic tool for business development and mechanism of differentiation of the corporate image.
\end{abstract}

Keywords: Sustainability. Competitiveness. Reutilization. Environment.

\section{Logística reversa fator de competitividade e sustentabilidade nas empresas}

\section{RESUMO}

$\mathrm{O}$ presente trabalho tem a finalidade de realizar um estudo acerca da logística reversa que incluem as questões ambientais e os resíduos industriais, que atualmente, é um assunto bastante abordado, por meio do conceito de produção sustentável. O objetivo Geral desta pesquisa é avaliar a logística reversa e o seu potencial competitivo e sustentável nas organizações. A pesquisa será na abordagem qualitativa, os procedimentos técnicos utilizados será do tipo pesquisa bibliográfica, com a finalidade de recolher e compilar informações para análise das diversas posições acerca do problema da pesquisa, levará em consideração as características que garantirão competitividade e sustentabilidade ás empresas nos eixos econômicos, social e ambiental por meio dos seus vários objetivos empresariais. Em síntese, analisando a acentuada preocupação de preservação e sobrevivência do planeta nas últimas décadas, a logística reversa passou a ser um instrumento estratégico para desenvolvimento empresarial e mecanismo de diferenciação da imagem corporativa.

Palavras-chave: Sustentabilidade. Competitividade. Reaproveitamento. Meio Ambiente.

\section{INTRODUÇÃO}

O mundo vive sob pressão, a globalização coloca em pauta os desastres ambientais, o destino do planeta, o aquecimento global, assim como, o provável esgotamento de insumos importantes para as indústrias.

Estas perspectivas acendeu o alerta para uma maior conscientização de preservação vinda de todas as áreas se caso, não se tome providências para controlar a poluição e todos os impactos negativos ambientais, a vida no planeta poderá se tornar inviável [1].
No que se refere a perspectiva ambiental origem para preocupações com relação ao desenvolvimento mundial e os recursos necessários para a sobrevivência, as corporações aparentemente estão mais interessadas em uma gestão empresarial sustentável, visando a atual conscientização ecológica sobre tudo suprir a essa nova demanda consciente, respondendo as pressões legais sociais e ambientais para amenizar a degradação causada ao meio ambiente e assim, promover desenvolvimento gradual para o negócio. 
Adriana de Souza Miranda, et al. / ITEGAM-JETIA Vol.02, Nº6, pp.98-104. Junho, 2016.

Analisando as exigências atuais de preservação ambiental, a logística reversa e suas influências servirá para diminuir os problemas com relação aos impactos ambientais, por meio do gerenciamento adequado do volume de resíduos sólidos e rejeitos gerados após o ciclo de vida útil dos produtos.

Desse modo, há necessidade que se criem estratégias para que ocorra equilíbrio entre os processos produtivos e os recursos naturais, que possam favorecer um desenvolvimento econômico de padrões sustentáveis.

Quando as organizações decidem adotar em sua gestão estratégica um sistema de logística reversa buscam criar de forma estratégica, canais reversos de responsabilidade pelo ciclo de vida dos seus produtos.

Diante do exposto surgiu a seguinte problemática. Como a logística reversa poderá ser um fator de competitividade e sustentabilidade nas empresas?

A justificativa acerca do estudo considera a importância da ferramenta logística reversa nas empresas, que adotam uma gestão ambiental competente e responsável pelos efeitos causados por seus produtos e serviços no meio ambiente, utilizam desse mecanismo para elaborar estratégias, atuando para reduzir impactos ambientais, levando em consideração a gestão ambiental e potencializando-se para alcançar ganhos de competitividade e sustentabilidade nas organizações.

O objetivo Geral desta pesquisa é avaliar a logística reversa e o seu potencial competitivo e sustentável nas organizações. E os seguintes objetivos específicos são: explicar como funcionam os fluxos diretos e reversos; verificar a influência do ciclo de vida dos produtos na prática reversa; identificar a eficiência dos canais reversos no alcance dos objetivos empresariais e ambientais; averiguar os impactos da logística reversa para estabelecer ganhos competitividade.

Contudo, existe nos últimos anos uma maior conscientização dos executivos de empresas no que se diz respeito ao valor ético empresarial como diferencial competitivo.

Empresas mais responsáveis estão buscando tomar ações que reduzam os impactos causados por seus produtos e processos ao meio ambiente.

\section{METODOLOGIA}

$\mathrm{Na}$ expectativa de encontrar respostas para a problemática da pesquisa será aplicada a abordagem qualitativa.

Atendendo ao critério de classificação da pesquisa indicado por [2], os procedimentos técnicos utilizados para o desenvolvimento do tema, constitui do tipo bibliográfica, elaborada a partir do levantamento de obras, pesquisas e trabalhos anteriormente realizados sobre o tema, analisadas e publicadas, por meio de livros, artigos científicos, dissertações, páginas de web sites dentre outras, com o propósito de recolher e compilar informações prévias para aquisição de diversos conhecimentos acerca do problema da pesquisa.

\section{LOGÍSTICA REVERSA FATOR DE COMPETITIVIDADE E SUSTENTABILIDADE NAS EMPRESAS}

\section{III.1. LOGÍSTICA REVERSA DEFINIÇÃO E APLICAÇÃO}

No cenário atual, muito se discute sobre os impactos ao meio ambiente, a questão desenvolvimento sustentável tornou-se uma preocupação mundial, as mídias anunciam constantemente as mudanças sofridas no planeta que impactam na sobrevivência e no progresso.

Supondo que, para reduzir os problemas causados ao meio ambiente, o lixo descartado inadequadamente na natureza, um dia já foi um produto. Por isso, para reduzir a poluição ambiental à logística reversa tratam do retorno dos materiais ao ciclo dos negócios, devido a crescente preocupação ecológica e com leis ambientais mais rígidas, as empresas estão se pautando da logística reversa como mecanismo para se tornarem mais competitivas e sustentáveis.

Para [3] define a logística reversa como sendo uma área que precisa ser devidamente administrada para que esta, possa agregar valor de diversas formas. Podemos observar a seguir: É a área da logística empresarial que planeja, opera e controla o fluxo e as informações logísticas correspondentes, do retorno dos bens de pós-vendas e de pós-consumo ao ciclo de negócios ou ao ciclo produtivo, por meio dos canais de distribuição reversos, agregando-lhes valores de diversas naturezas: econômico, de prestação de serviços, ecológico, legal, logístico, de imagem corporativa dentre outros.

Constata-se que a logística reversa, precisa ser bem conduzida para que os produtos de pós-venda e pós-consumo retornem por meio de seus canais reversos de distribuição para que estes adicionem valor, seja, por caráter ambiental, coorporativo, legal entre outras razões.

De acordo com [4] apresentam uma definição transdisciplinar que explica a logística reversa como uma cadeia de beneficiamento que deverá minimizar os impactos negativos maximizando os impactos positivos, conseguinte: É o processo de recuperação dos resíduos de pós-venda ou pós- consumo, pela coleta, pré-tratamento, beneficiamento e distribuição, de forma a ou retorná-los a cadeia produtiva, ou dar-lhes destinação final adequada. Deve enfocar a minimização dos rejeitos e dos impactos negativos e a maximização dos impactos positivos, sejam ambientais, sociais e econômicos.

Entende-se que, a cadeia reversa recupera os resíduos de produtos após serem consumidos ou vendidos do tratamento a destinação final, com a finalidade de maximizar os impactos positivos, beneficiando a cadeia produtiva e o ambiente externo organizacional. 


\section{III.2. CANAIS DE DISTRIBUIÇÃO DIRETOS E REVERSOS}

De acordo com [3] os canais de distribuição diretos, ou somente canais de distribuição como são comumente conhecidos, são formados por diversas etapas pelas quais bens e serviços são produzidos e comercializados, até chegar nos consumidores finais, seja uma empresa ou uma pessoa física.

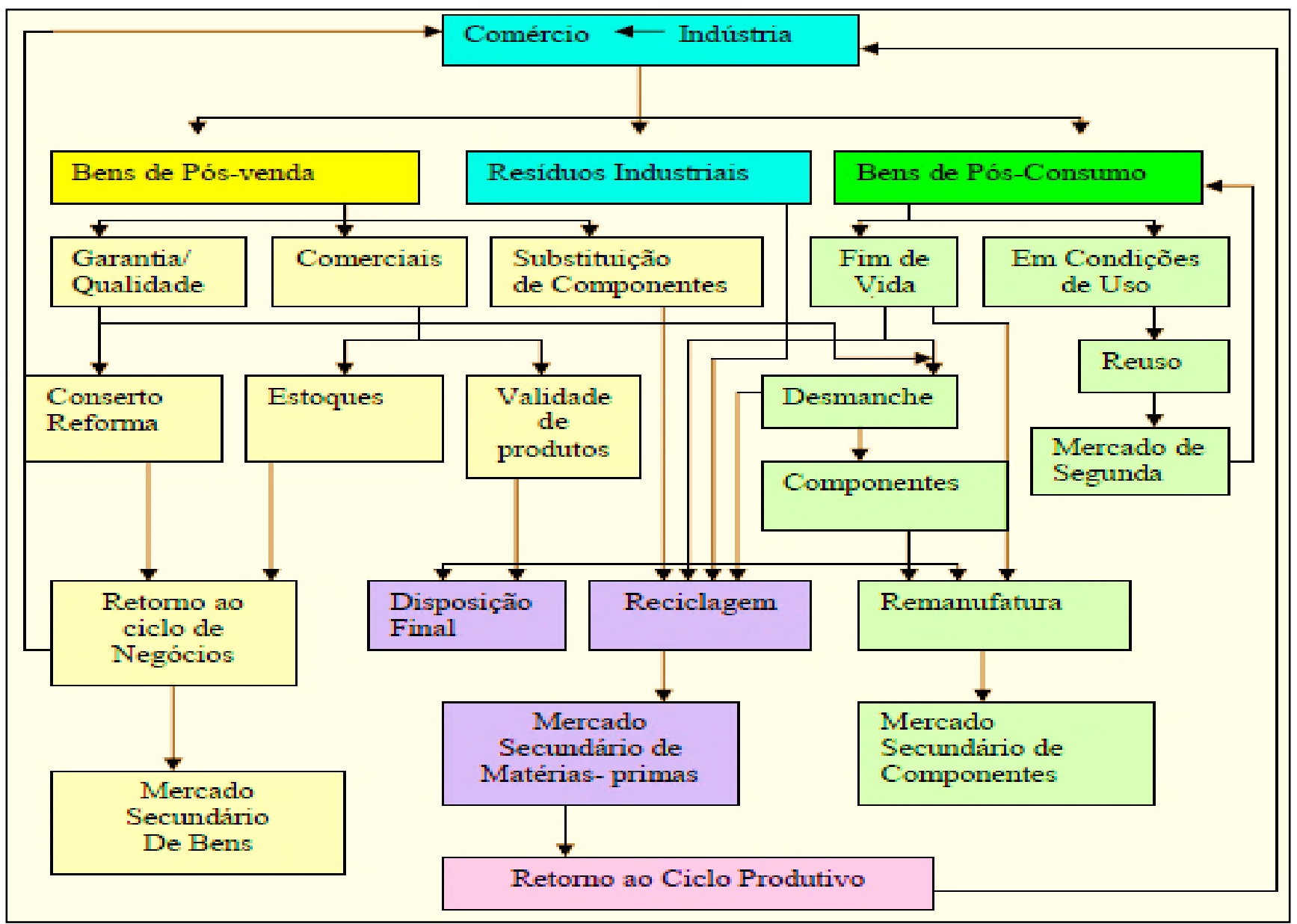

Figura 1- Foco de atuação da Logística Reversa.

Fonte: Leite $(2009,9.20)$.

Segundo [3] a logística pós-venda: são produtos que retornam ao ciclo produtivo por defeitos de fabricação ou funcionamento; diversos motivos comerciais; recall, ou seja, término de validade ou problemas observados após a venda; substituições de componentes para manutenções ou consertos.

Assim, a logística pós-consumo: são produtos que retornam dependendo das condições de uso para o reuso; ou serem recuperados, reaproveitados em outros processos; ou até mesmo quando chegam ao fim do seu ciclo de vida útil recebem uma disposição final adequada.
Simplificando, o termo logística reversa no âmbito empresarial, pode-se afirmar, que é uma ferramenta importante ao se tratar do gerenciamento adequado que reincorporam os resíduos ao ciclo produtivo, por meio de reciclagem, reutilização, reuso, técnicas de manutenção e consertos, retorno, e destinação final adequada inclusos em seus canais reversos de pós-venda e pós-consumo beneficiando a revalorização dos bens produzidos na cadeia produtiva. 


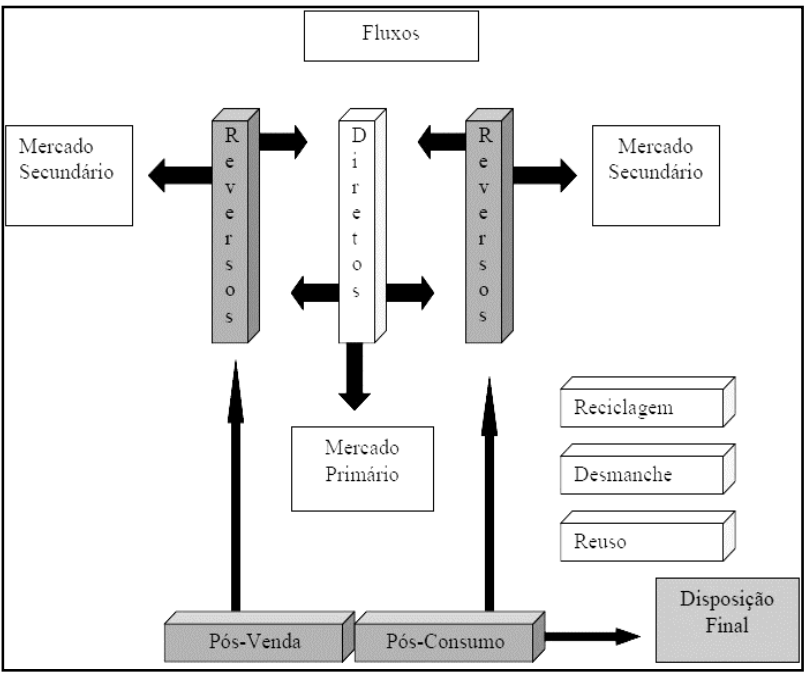

Figura 2: Canais de distribuição diretos e reversos.

Fonte: Leite (2009, p.7).

Verifica-se que, os canais de distribuição são meios para entregar bens e serviços produzidos e comercializados aos consumidores finais. Esses canais escoam de acordo com o fluxo correspondente direto ou reverso.

Para melhor compreensão da logística reversa, [5] destaca os seguintes tipos de fluxos de operações logísticas como sendo o fluxo direto e o fluxo reverso, nestes escoam informações, materiais e produtos. Assim, o fluxo direto segue desde a origem um curso de escoamento contínuo para entregar ao cliente ou em um local; o fluxo reverso são as atividades que retornam do consumidor final ou de qualquer outro membro da cadeia, por fim de vida útil ou problemas específicos no desenvolvimento de um produto acabado.

Portanto, as organizações que administram a cadeia de suprimentos e gerenciam o fluxo reverso em seus diferentes processos, orientam o curso de seus produtos desde a criação, distribuição, entrega ao cliente e devolução para que estes retornem a cadeia produtiva.

"Esse fluxo reverso precisa ser gerenciado para obtenção de ganho sustentável expressivo nos negócios” [6].

Faz-se necessário controlar as operações, planejar detalhadamente cada atividade para que os canais de distribuição reversos funcionem efetivamente, seja por competitividade cumprimento legal, preservação ambiental, aproveitamento econômico ou melhoria de imagem perante o mercado.

\section{III.3. RESPONSABILIDADE EMPRESARIAL E SUSTENTABILIDADE}

O conceito triple bottomline na conscientização ecológica, segundo [7], enfatiza sobre a importância de avaliar os efeitos das decisões de negócios sobre três áreas fundamentais: meio ambiente (planeta), social (pessoas) e econômica (lucro), para a empresa ser sustentável deve considerar os impactos de suas atividades desenvolvidas relacionando os três elementos base para o avanço, responsabilidade ética empresarial que contribui com o bem-estar e o futuro da sociedade.

Conforme as três áreas apresentadas no conceito triple bottonline a sustentabilidade econômica combina a preservação do meio ambiente com o retorno financeiro, as organizações em defesa de seus próprios interesses.

Utilizam a sustentabilidade como oportunidade econômica de reputação ética, a sociedade e seus vínculos desenvolve-se por meio de seus direitos e suas leis, em busca de condições mais dignas como, por exemplo: melhor qualidade de vida, emprego, renda, atitudes ética entre outros.

Segundo [8], as dimensões da sustentabilidade são: sustentabilidade social: apoia-se no premissa da igualdade na distribuição de renda e de bens; igualdade de direitos a dignidade humana e no fundamento dos laços sociais;sustentabilidade ambiental: premissa da preservação do planeta e dos recursos naturais;sustentabilidade econômica: avaliada apartir da sustentabilidade social e ambiental, auxiliando as empresas a obterem lucro com resposabilidade.

Sobretudo, analisando as três dimensões da sustentabilidade é possível observar que só ocorre sustentabilidade econômica se houver sustentabilidade social e ambiental, pois, a mesma deve está empregada às três vertentes, ou seja, o meio ambiente precisa ser preservado para que a sociedade possa viver e se desenvolver.

Logo, seguindo os seus preceitos, as empresas para se desenvolver economicamente dependem do meio ambiente e os seus recursos, assim como da sociedade e sua existência.

De acordo com [9], o desenvolvimento sustentável, traduz-se frequentemente com o auxílio de métodos como a reciclagem, o reuso, a recuperação e o gerenciamento dos resíduos.

Para facilitar a utilização desses métodos, as empresas empregam ao seu funcionamento canais de distribuição reversos que se reincorporam bens de pós-venda ou pós-consumo ao ciclo produtivo.

A sustentabilidade tem como fundamento, conduzir a inovação na concepção de produtos e na fabricação por meio de novas matérias primas e processos mais limpos, ao uso e destinação final dos materiais de forma que, ocorra o reaproveitamento e não agressão ao meio ambiente e conseguinte a vida no planeta [10].

Entende-se que, a Logística Reversa é um instrumento de desenvolvimento econômico e social, que proporciona ao setor empresarial seguir ações sustentáveis em seus procedimentos produtivos ao consumo. Envolve técnicas de restauração, possibilitando a coleta, o retorno à cadeia produtiva 
e destinação ambientalmente adequada sem comprometer a vida e a qualidade ambiental.

O conceito Logística reversa, ampara-se precisamente na sustentabilidade ecológica e econômica. De acordo com as possibilidades, as organizações podem gerar lucros e riquezas ao mesmo tempo adotando práticas sustentáveis que lhe tragam benefícios proveitosos com a preservação do meio ambiente para as gerações futuras, o que permiti proporcionar sustentabilidade social respeitando a comunidade local envolvida, gerando emprego e renda [8].

Compreende-se que, os empreendimentos de negócios que são capazes de manter em seu desenvolvimento econômico, estratégias de decisões com dimensões sociais e ambientais compatíveis com a preservação ambiental, permitem o desenvolvimento e a sobrevivência das futuras gerações.

\section{III.4. ESTRATÉGIA DE NEGÓCIOS NA CADEIA DE SUPRIMENTO REVERSA}

Observa-se que, a logística reversa é a parte do que se conhece como gestão da cadeia de suprimento um ciclo fechado que vem ganhando importância como uma estratégia de negócio ambiental, lucrativa e sustentável [11].

Preocupando-se com a implementação, controle da eficiência e custo efetivo do fluxo de matéria-prima, gradativamente, as empresas se modernizam para adequação a novos nichos de mercado e garantir produtividade, qualidade de serviços e produtos oferecidos a clientes.

A perspectiva estratégica de logística reversa no macro ambiente e empresarial é formado pela sociedade e comunidades locais, governos e ambiente concorrencial, levando em consideração as características que venha garantir competitividade e sustentabilidade nos eixos econômicos e ambientais. Na busca de recuperação de valor financeiro; legislações; prestação de serviços aos clientes e mitigação dos riscos [3].

Enfatizando, o gerenciamento do volume de resíduos e rejeitos gerados após a vida útil dos produtos, exigem estratégias para que ocorra equilíbrio entre os processos produtivos e os recursos que possam favorecer um desenvolvimento econômico sem comprometer a vida e o sucesso empresarial.

Marketing Verde está diretamente ligado à sustentabilidade, as organizações estão utilizando cada vez mais essa nova vertente como estratégia em seus negócios, possibilitando à divulgação de ações sustentáveis. Além do cumprimento da legislação ambiental, a exposição do foco nas necessidades e desejos de seus clientes e na conscientização da preservação do meio [12].

Averígua-se que, uma empresa ao ser sustentável, ela deve ter indicadores que demonstre esta alternativa aos clientes, caso contrário ela perderá credibilidade no mercado porque envolve toda uma campanha voltada para a ética e sustentabilidade.

\section{III.5. AVALIAÇÃO DO CICLO DE VIDA E A LOGÍSTICA REVERSA}

Conforme [8], a avaliação do ciclo de vida é conhecida pelo termo berço à cova, berço nascimento extração dos insumos, cova destino final dos resíduos.

O conceito refere-se a tudo que for produzido se não reusado ou reciclado deverá ser incinerado ou disposto em aterro, ou seja, a cova é destinação ambiental adequada, este ciclo difere do mercadológico nascimento do produto, crescimento da demanda, maturidade e declínio.

Em sumula, o ciclo de vida do produto, representa sua história que vai desde a obtenção dos recursos indispensáveis, extração da matéria, todas as etapas de operacionalização ao uso, o seu pós-consumo de retorno ao ciclo produtivo até a destinação final, caso não venha ser mais utilizado ele terá seu destino próprio, contribuindo com o meio ambiente.

Ao considerar esses resíduos muitas vezes nocivos à saúde, podem ser revalorizados economicamente, surge um novo conceito berço a berço que ambientalmente é mais eficiente, neste, os resíduos são reinseridos a novos produtos, processos e negócios, totalmente reutilizados para reduzir o descarte no meio ambiente.

Esse novo conceito, propõe o consumo e o desenvolvimento contínuo, portanto, a logística reversa se aplica totalmente ao modelo berço a berço" [8].

Figura 3 - Ciclo de vida de um produto

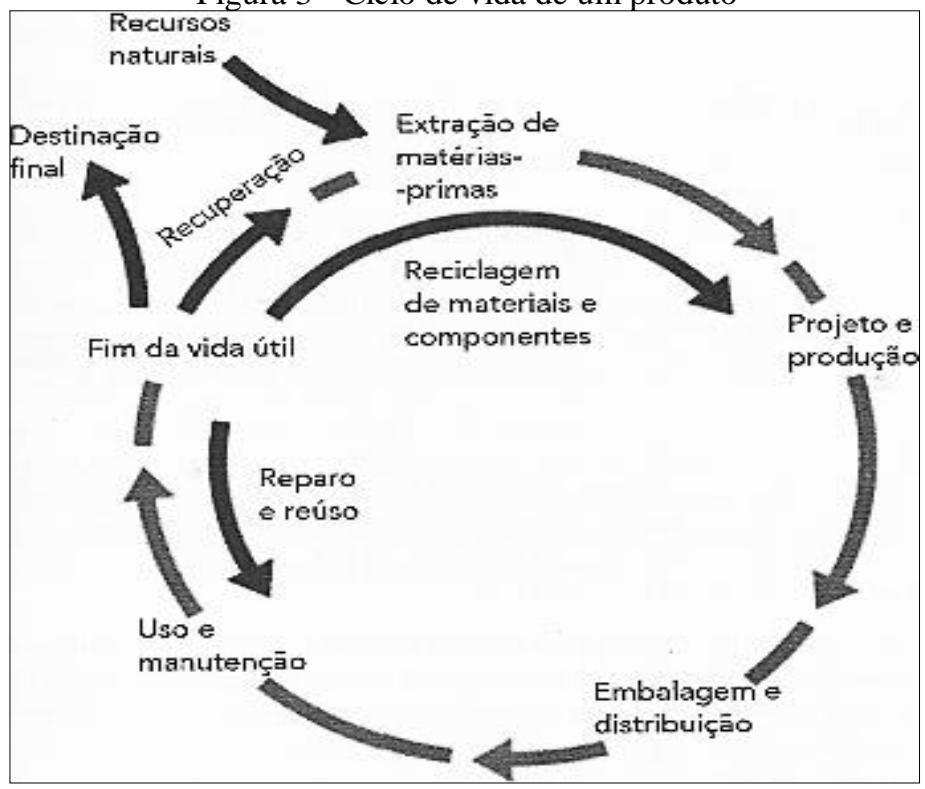

Fonte: UNEP, (2009).

Avaliando o ciclo de vida, surge um método fundamental usado pelas empresas fabricantes para analisar quais 
impactos seus produtos irão causar ao meio ambiente desde a seleção dos insumos a destinação final.

As constantes transformações como competição das indústrias, lançamento de produtos diferenciados, inovações tecnológicas, designs diversos e novas funcionalidades são fatores que contribuem para encurtar o tempo de vida útil de um produto.

$\mathrm{Na}$ medida em que as empresas elaboram diversos modelos de produtos para satisfazer diferentes clientes, o aumento do consumo reduziu o ciclo de vida dos produtos, sendo substituídos com maior frequência, devido sua a pouca utilização, são logo descartados e quando despejados em local inadequado degradam o meio ambiente.

"Com a preocupação ambiental em preservar o meio ambiente, existe uma clara tendência de que a legislação ambiental caminhe no sentido de tornar as empresas cada vez mais responsáveis pelo ciclo de vida de seus produtos" [6].

\section{III.6. SISTEMA DE LOGÍSTICA REVERSA, POTENCIAL COMPETITIVO}

De acordo com [3], “a logística reversa traz vantagens competitivas, a questão da preservação ambiental contribui para o marketing sócio ambiental, construção de uma imagem corporativa de responsabilidade ética empresarial".

As empresas estão se modernizando e buscando investir em projetos de logística reversa que visam melhorar as condições de reaproveitamento, criam parcerias com outras instituições para incentivar a reciclagem e reuso, investindo em programas educacionais de conscientização social para solucionar problemas ambientais e legais, atuam para obter em sólidos ganhos econômicos e uma imagem diferenciada.

Em síntese, as ações que envolvem a sustentabilidade ambiental nas cadeias produtivas colaboram para melhorar a estrutura e a organização dos canais reversos. Formando redes de distribuição reversa que agregam valor aos produtos e serviços, gerando novas oportunidades de negócios e lucro, essa nova cultura ambientalista tem o poder de conquistar o mercado consumidor.

A operacionalização da logística reversa para [8], representa uma vantagem competitiva. A empresa ao empregar sua conduta ética e práticas ambientais sérias, além de estruturação, terá reconhecimento no mercado consumidor. Sua imagem poderá ser extremamente valorizada, a competitividade deixa muitas empresas no mesmo nível de igualdade no que se refere a preço e qualidade de produtos e serviços.

Em súmula, a logística reversa surge como um elemento diferenciador entre os concorrentes, capaz de intensificar o aumento da satisfação do cliente e da rentabilidade da empresa ao mesmo tempo.
Portanto, [8] considera que uma empresa poderá ter sua imagem comprometida, quando decidir divulgar, que possuí práticas de logística e gestão ambiental, porém falsas e incipientes, praticando na verdade "greenwashing" ou "lavagem verde" uma analogia a lavagem de dinheiro, demonstram assim, a falta de ética, desrespeitando o mercado consumidor e a sociedade. Pois, são penalizadas com a desvalorização de sua imagem corporativa.

Diante do exposto, pode-se compreender que as empresas ao decidirem ter um posicionamento ambiental, deverão tomar decisões sérias e legítimas, levam deste modo anos para construírem uma reputação consistente perante o mercado consumidor e podem perder toda a credibilidade conquistada, assim como, perdem seus investimentos e competitividade.

\section{CONSIDERAÇÕES FINAIS}

Respondendo a problemática dos resultados pesquisados, a Logística Reversa é uma maneira de fazer negócios partindo do princípio da sustentabilidade.

Por mais que possa parecer para as empresas que vai gerar custo ou mais despesa e quando na verdade ela é o lucro sustentável, onde futuramente alcançará o mesmo patamar ou ter mais lucro.

A empresa tem a responsabilidade de estabelecer com todas as partes envolvida, uma relação ética transparente e um planejamento estratégico de atender às expectativas de todas e não só dos acionistas.

Os benefícios gerados por essa conduta, nada mais é que a lucratividade, a boa imagem corporativa, a credibilidade quando lidam com a questão de resíduos, energia e uma série de questões que hoje impactam brutalmente no custo de operação.

O sucesso vem a médio e longo prazo, o acesso ao capital são prósperas, a imagem é mais positiva gerando ambiente mais favorável ao seu crescimento, hoje é um jeito de fazer negócio pensando na sua perenidade.

Por isso a responsabilidade ambiental para as organizações não impede seu crescimento econômico, muito pelo contrário é ela a responsável pelo sucesso das organizações no cenário atual.

\section{AGRADECIMENTOS}

Ao Instituto de Tecnologia e Educação Galileo da Amazônia (ITEGAM), ao PPGEP do Instituto de Tecnologia Universidade Federal do Pará (ITEC-UFPA) e a Universidade Estácio de Sá pelo apoio financeiro a pesquisa. 
[1] VIEIRA, H. F. Gestão de Estoques e Operações Industriais. 1. ed. Curitiba, PR: IESDE Brasil S.A, 2009, 316 p.

[2] VERGARA, S. C. Tipos de pesquisa em administração. Cadernos EBAP - Fundação Getúlio Vargas, Rio de Janeiro, n.52, jun. 1990.

[3] LEITE, P. R. Logística Reversa Meio Ambiente e Competitividade. 2. ed. São Paulo: Pearson Prentice Hall, 2009, $240 \mathrm{p}$.

[4] COSTA, L.; MENDONÇA, F. M.; SOUZA, R. G. O que é Logística Reversa: logística reversa uma definição transdisciplinar. In: SOUZA, R. G.; VALLE, R. Logística Reversa Processo a Processo. São Paulo: Editora Atlas S.A., 2014, Cap. 2, p. 18-33.

[5] FERNANDES, K. S. Logística: fundamentos e processos. 1. ed. Curitiba, PR: IESDE Brasil S.A, 2012, 160 p.

[6] NOGUEIRA, A. S. Logística Empresarial - Uma visão local com pensamento globalizado. 1. ed. São Paulo: Editora Atlas S.A., 2012, 206 p.

[7] CHRISTOPHER, M. Logística e Gerenciamento da Cadeia de Suprimentos. 4. ed. São Paulo: Cengage Learning, 2013, 332 p.

[8] GUARNIERI, P. Logística Reversa em Busca do Equilíbrio Econômico e Ambiental. 1. ed. Recife: Clube de Autores, 2011, 307 p.

[9] MENDONÇA, F. M.; PONTES, A. T.; SOUZA, R. G. Logística Reversa, Meio Ambiente e Sociedade. In: SOUZA, R. G.; VALLE, R. Logística Reversa Processo a Processo. São Paulo: Editora Atlas S.A., 2014, Cap. 1, p. 05-17.

[10] SALGADO, T. T. Logística: práticas, técnicas e processos de melhorias. 1. ed. São Paulo: Senac Editoras, 2013, 165 p.

[11] GRANT, D. B. Gestão de Logística e Cadeia de Suprimentos. 1. ed. São Paulo: Editora Saraiva, 2013, 362 p.

[12] BAROTO, A. Gestão Ambiental: responsabilidade social e sustentabilidade. 2008. Disponível em: http://www.administradores. com.br/ artigos/negócios/marketing -verde -uma-estrategia-demarketing-utilizando-praticasambientais /62727/. Acesso em: 15 nov. 2015. 